\title{
The Use of Blockchain Technology in the Health Care Sector: Systematic Review
}

Deepa Elangovan ${ }^{1}$, BPharm (Hons); Chiau Soon Long ${ }^{2}$, BSc; Faizah Safina Bakrin ${ }^{1}$, PhD; Ching Siang Tan ${ }^{1}$, PhD; Khang Wen Goh ${ }^{3}$, PhD; Siang Fei Yeoh ${ }^{4}$, MClinPharm; Mei Jun Loy ${ }^{5}$, BEng (Hons); Zahid Hussain ${ }^{6}$, PhD; Kah Seng Lee $^{7}, \mathrm{PhD}$; Azam Che Idris ${ }^{8}, \mathrm{PhD} ;$ Long Chiau Ming ${ }^{9}, \mathrm{PhD}$

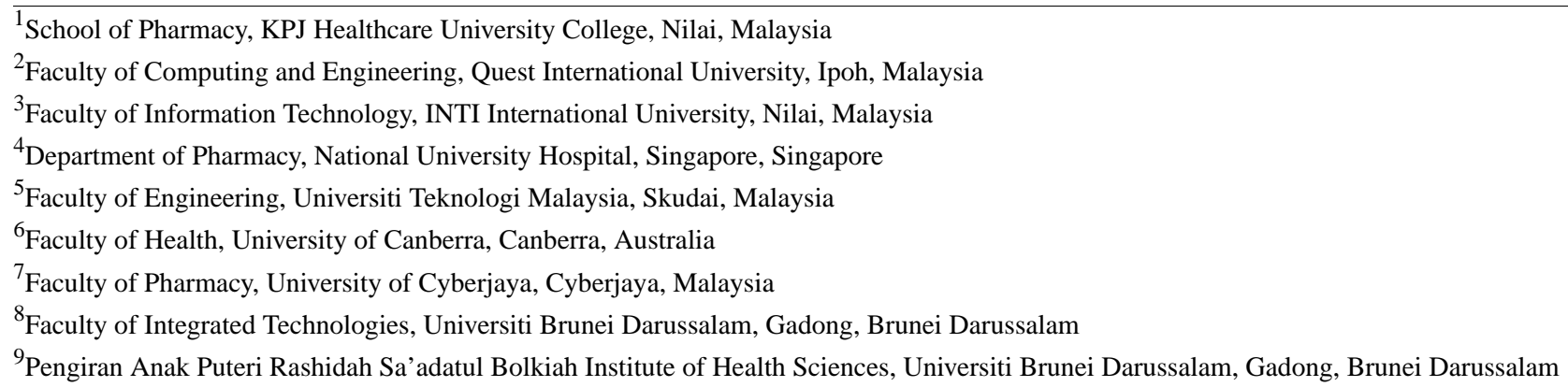

\section{Corresponding Author:}

Khang Wen Goh, PhD

Faculty of Information Technology

INTI International University

Persiaran Perdana BBN Putra Nilai

Nilai, 71800

Malaysia

Phone: 6067982000

Email: khangwen.goh@newinti.edu.my

\section{Abstract}

Background: Blockchain technology is a part of Industry 4.0's new Internet of Things applications: decentralized systems, distributed ledgers, and immutable and cryptographically secure technology. This technology entails a series of transaction lists with identical copies shared and retained by different groups or parties. One field where blockchain technology has tremendous potential is health care, due to the more patient-centric approach to the health care system as well as blockchain's ability to connect disparate systems and increase the accuracy of electronic health records.

Objective: The aim of this study was to systematically review studies on the use of blockchain technology in health care and to analyze the characteristics of the studies that have implemented blockchain technology.

Methods: This study used a systematic review methodology to find literature related to the implementation aspect of blockchain technology in health care. Relevant papers were searched for using PubMed, SpringerLink, IEEE Xplore, Embase, Scopus, and EBSCOhost. A quality assessment of literature was performed on the 22 selected papers by assessing their trustworthiness and relevance.

Results: After full screening, 22 papers were included. A table of evidence was constructed, and the results of the selected papers were interpreted. The results of scoring for measuring the quality of the publications were obtained and interpreted. Out of 22 papers, a total of $3(14 \%)$ high-quality papers, $9(41 \%)$ moderate-quality papers, and 10 (45\%) low-quality papers were identified.

Conclusions: Blockchain technology was found to be useful in real health care environments, including for the management of electronic medical records, biomedical research and education, remote patient monitoring, pharmaceutical supply chains, health insurance claims, health data analytics, and other potential areas. The main reasons for the implementation of blockchain technology in the health care sector were identified as data integrity, access control, data logging, data versioning, and nonrepudiation. The findings could help the scientific community to understand the implementation aspect of blockchain technology. The results from this study help in recognizing the accessibility and use of blockchain technology in the health care sector. 
(JMIR Med Inform 2022;10(1):e17278) doi: 10.2196/17278

\section{KEYWORDS}

blockchain; health care; hospital information system; data integrity; access control; data logging; health informatics

\section{Introduction}

Health informatics (HI) is an extension of medical informatics that concentrates on the clinical sector and implementation of technology in the distribution of health care [1]. Changes in both technology and health care are leading to the evolution of health care informatics. With current technology, HI provides fundamental, indivisible knowledge bases to health professionals and health care organizations to provide patients with a better quality of care services [2]. Acquiring and recording medical and patient information, liaising with health care professionals, choosing an appropriate diagnostic method, elucidating laboratory findings, and gathering clinical research information are known as information processing and communication in the health care sector [3].

Electronic health record (EHR) systems and hospital information systems (HISs) are widely used across the world. However, the current HISs are mainly cloud based, are stored by one particular data contractor, and have several disadvantages, such as a lack of sufficient security measures. This has led to innumerable breaches of data, as well as issues of data validity and data sharing, which have left patients exposed to economic threats and possible social stigma. Centralized data or information is an appealing target for cyberattacks, and issues arise due to establishing a persistent view of the patient data across a network [4].

Taking these issues into consideration, an improved tamperproof and hackproof database management system is much needed to replace the current system that has been used for the past several decades. The new innovative system should have better data security and be able to integrate with other information technology (IT) systems, such as finance and admission systems. When blockchain technology was introduced in 2008, it largely fulfilled all of these criteria, alongside its versatility for applications in banking and finance.

Blockchain is a decentralized database that maintains an uninterrupted, growing list of data records that are established by the nodes involved. The information is recorded in a public ledger that includes data from every completed transaction [5]. Along with this, blockchain is also a sort of dispersed ledger of cryptographically chained blocks where value-exchanged transactions are consecutively aggregated. Blockchain also exhibits properties such as decentralization, security, anonymity, and data integrity with the absence of a mediator to control agreement and inalterability [6]. The information in blockchain is transparent and tamperproof due to the continuous series of blocks, which contain information and data [7].

Blockchain is a decentralized database that is not owned by anybody and is simultaneously owned by everybody, as the contents are available to all parties involved. For example, with Bitcoin, since all transactions are processed by users via a particular pseudonym, the information contained in the blockchain is completely anonymous [8]. This revolutionary system has indeed overcome some of the limitations faced by the existing system. Nevertheless, further exploration in terms of implementation and practicality is much needed and will be discussed in the following sections [9].

This study aimed to systematically review studies on the use of blockchain technology in health care. We also analyzed the characteristics of the studies that have implemented blockchain technology. This study will be impactful in helping the scientific community to understand the use aspect of blockchain technology based on the findings of completed studies. The results from this study will help to identify the accessibility as well as the implementation of blockchain technology in the health care sector.

\section{Methods}

\section{Study Design}

The methodology used in this research was a systematic review, modeled on a recent systematic review about blockchain reported by Böhme et al [7].

\section{Data Sources and Search Strategy}

A search was conducted for scientific papers on the research topics. All papers that were relevant for these topics were gathered by using a search protocol that was developed for each scientific database. Possible keywords were tested, and appropriate terms were chosen for the search string. The Medical Subject Headings (MeSH) database was used to derive keywords and search term combinations. PubMed, SpringerLink, IEEE Xplore, Scopus, Embase, and EBSCOhost databases were chosen to search for all the relevant literature. The search strings were constructed in accordance with the research domains and research questions and are listed in Multimedia Appendix 1.

Online digital libraries were used to search for relevant papers from January 2008 to September 2019. The year 2008 was chosen as the beginning of the range for this research study because the first published application of blockchain technology (ie, Bitcoin) was introduced in that year, so no blockchain-related studies were conducted before 2008. In this systematic review, the search query was purposely made broad, in order to identify many papers related to the research question. However, when "Bitcoin" was used as a search term, a large number of papers were identified, but the papers were mainly about economic applications rather than applications in the health care sector.

Because the aim of this research was based on finding and mapping the papers related to blockchain technology in the health care sector, "Bitcoin" was dropped as a search term. By using "blockchain" and "health care" as search terms, the majority of Bitcoin-related papers with a technical perspective on blockchain were still included. A manual search was carried 
out for papers that were published at workshops, at conferences, in journals, and at symposiums.

\section{Study Selection}

\section{Screening of Relevant Papers}

The next step in the process was screening relevant papers, wherein the papers that had been found during the previous step were assessed for actual relevance. The screening process started with all of the publications gathered from online digital libraries. A process inspired by Yli-Huumo et al [10] was used to screen for relevant papers. Applicable quotes from the search were entered into, and sorted with the aid of, EndNote X8.0 (Clarivate), which was used to remove duplicate papers. Duplicate references across databases and references that were not appropriate for the study were eliminated from the literature search reference lists. The remaining duplicates were deleted manually.

The iterative approach for title, abstract, and full-text searches was used, and the results were exported to Microsoft Excel 2013. The titles and abstracts of the searched papers were screened first to determine the relevance or appropriateness for this systematic review. At this stage, studies that were clearly not about the use of blockchain technology in health care were excluded. The titles and abstracts were screened by two reviewers based on the inclusion and exclusion criteria.

\section{Inclusion and Exclusion Criteria}

The papers that had passed the previous screening phase were screened based on their abstract. In addition, the following specific inclusion and exclusion criteria were used to screen each paper:

1. Inclusion criteria:

a. Original research study.

b. Study in English.

c. Publication on blockchain technology in the health care sector.

d. Publication including sufficient explanation of the research findings.

2. Exclusion criteria:

a. Papers without full-text availability.

b. Papers for which English was not the main language.

c. Papers that had some other focus instead of the use of blockchain in the health care sector.

d. Papers that were duplicates.

e. Search results that were editorials, prefaces, paper summaries, summaries of tutorials, interviews, news items, correspondences, discussions, comments, readers' letters, workshops, panels, and poster sessions.

f. Publications indicating ideas, magazine publications, and discussion papers.

\section{Abstract Screening Based on Keywords}

Screening based on keywords, as defined by Dyba and Dingsøyr [11], was done in two steps. In the first step, identifiable keywords and concepts from the abstracts were analyzed that reflected the contribution of the papers. Developing a greater level of understanding based on these keywords was the second step in this keywording process.

The keywords were used to cluster and form categories. All the selected papers were read after the categories had been clustered. The categories were updated after reading each paper, or if the paper revealed something new, then a new category was created. This step resulted in clustered categories being formed from all the relevant papers based on this research topic. Papers with poor, misleading, or lost abstracts were excluded due to irrelevant information.

After the title-, abstract-, and keyword-screening process, each remaining paper underwent full-text screening based on the same eligibility criteria. Two reviewers resolved discrepancies through discussion, and no adjudication by a third reviewer was required.

\section{Data Gathering and Data Extraction}

A template was designed to collect the information required to address the research question. Basic metadata about the publication were collected, such as author name and country, year of publication, source type, and type of publisher.

To categorize the 22 selected papers, further data were extracted. Each full paper was read to extract the keywords or outcomes related to our research question; these were then sorted into the identified categories, as follows:

1. Use cases of blockchain technology in health care that indicate the specific health care area, such as electronic medical records (EMRs), biomedical research and education, remote patient monitoring, drug or pharmaceutical supply chains, health insurance claims, health data analytics, or other areas.

2. Reasons for using blockchain technology in health care, such as data integrity, access control, logging, data versioning, and nonrepudiation.

\section{Literature Quality Assessment}

An assessment of literature quality was performed. All of the final 22 publications were independently reviewed and scored by two reviewers. The assessment tool for blockchain-related studies proposed by Petersen et al [12] was used to critically appraise and summarize evidence in the searched papers.

In accordance with Hölbl et al [13], the quality of the papers was assessed using the criteria defined in Table 1.

This tool was used to assess the trustworthiness, relevance, and results of the published papers. These led to the decision of which papers were believable and useful and could be used for the research. A three-tier scale was used to rank the quality of all four questions. A value of 0 ("barely" or "no") was assigned when the criterion was addressed very poorly or not at all, a value of 1 ("partially") was assigned when a criterion was partially addressed, and a value of 2 ("satisfactorily" or "yes") was assigned when the reviewer felt that the publication had successfully satisfied the criterion.

Two reviewers assessed each query from question 1 (Q1) to question $4(\mathrm{Q} 4)$, which resulted in a minimum of 0 points to a maximum of 4 points per query. The minimum score for the 
sum of responses to question $2(\mathrm{Q} 2)$, question $3(\mathrm{Q} 3)$, and Q4 was 0 points, and the maximum score was 12 points. The score of the response to Q1 was converted to $40 \%$ of the total value, and the total summed score of responses to Q2, Q3, and Q4 was converted to $60 \%$ of the total value, with Q2, Q3, and Q4 each contributing $20 \%$ of the total points.

So, the overall score was the sum of responses to Q1 to Q4, which is presented as a percentage to enhance readability and comprehension. An explanation of scoring of responses to queries Q1 to Q4 is given in Table 1.

To find the percentage score of the response to Q1, the following equation applies:

$$
\frac{\text { Total score given by reviewers }}{4 \text { (maximum score) }} \times 40 \%
$$

To find the percentage score for the sum of responses to Q2 to $\mathrm{Q} 4$, the following equation applies:

$$
\frac{\text { Total score given by reviewers }}{12 \text { (maximum score) }} \times 60 \%
$$

The overall score is represented by the following equation: Overall score $=$ Percentage score of response to Q1 $(\%)+$ Percentage score of sum of responses to Q2 to Q4 (\%) [13].

From the calculation, the publications that have an overall score of $90 \%$ and above are high-quality papers. An overall score between $80 \%$ and $89 \%$ indicates a moderate-quality paper, and low-quality papers are represented by an overall score of $79 \%$ or less.

Table 1. Parameters for measuring quality of the publications [13].

\begin{tabular}{lll}
\hline Question (Q) & Quality assessment query & Responses (scores) \\
\hline Q1 & Is the publication relevant to blockchain? & "barely" (0), "partially" (1), or "satisfactorily" (2) \\
Q2 & Does the publication include and define research objectives adequately? & "no" (0), "partially" (1), or "yes" (2) \\
Q3 & Are limitations and challenges well defined? & "no" (0), "partially" (1), or "yes" (2) \\
Q4 & Is the proposed contribution well described? & "no" (0), "partially" (1), or "yes" (2) \\
\hline
\end{tabular}

\section{Data Availability}

All data have been reported in this manuscript.

\section{Results}

\section{Study Selection}

A total of 271 papers were initially retrieved as a result of implementation of the search protocol that was designed for searching the selected scientific databases. Of the 271 papers, $34(12.5 \%)$ were from PubMed, $52(19.2 \%)$ were from SpringerLink, 40 (14.8\%) were from IEEE Xplore, 56 (20.7\%) were from Embase, 45 (16.6\%) were from Scopus, and 44 (16.2\%) were from EBSCOhost. Then, the first screening was done based on the titles of the retrieved papers. All of the paper titles were examined independently by one reviewer based on the inclusion and exclusion criteria, which led to the selection of 175 papers. In the first screening, a total of 52 papers were excluded because they were not related to the research topic (eg, some excluded papers discussed the business perspective of Bitcoin rather than the use of blockchain technology in the health care sector). Meanwhile, 25 papers related to other scientific areas, such as mathematics and chemistry, were excluded from the first screening, as the term "blockchain" had other meanings apart from the technology used in computer science and IT. Through a manual search and using references from the included papers, an additional 10 papers were collected.
After the selection of 185 papers from the first screening, 87 duplicate papers were removed using Endnote X8. This resulted in 98 papers, which underwent further screening based on abstracts where, in some cases, the introduction and conclusion of the full text were analyzed. The abstracts of all the selected papers were read by two reviewers. Some of the papers were removed because the abstracts indicated no relevance to the research topic. The unclear or grey-area abstracts or papers were moved to the next screening step for more in-depth analysis.

A total of 35 papers were identified for full-paper analysis, which was the last stage of paper selection for this systematic review. Each paper was read in full, independently, and assessed for eligibility using the inclusion and exclusion criteria. This resulted in the selection of 22 primary papers. Of the 35 papers identified for full-text analysis, $3(9 \%)$ were dropped because they focused on the economic perspective of Bitcoin and not the health care setting. Of the 35 papers, 5 (14\%) were removed as they only described blockchain and how it works, without discussing any actual blockchain implementation in a real health care environment. Furthermore, 3 out of 35 (9\%) papers identified as review papers and $2(6 \%)$ papers identified as proposal papers were removed. Figure 1 shows the results of the search strategy. The list of 22 selected primary papers and the extracted data items are included in Table 2 [14-35]. The PRISMA (Preferred Reporting Items for Systematic Reviews and Meta-Analyses) checklist for this research study on the use of blockchain technology in the health care sector is included in Multimedia Appendix 2. 
Figure 1. PRISMA (Preferred Reporting Items for Systematic Reviews and Meta-Analyses) flowchart of the search strategy.

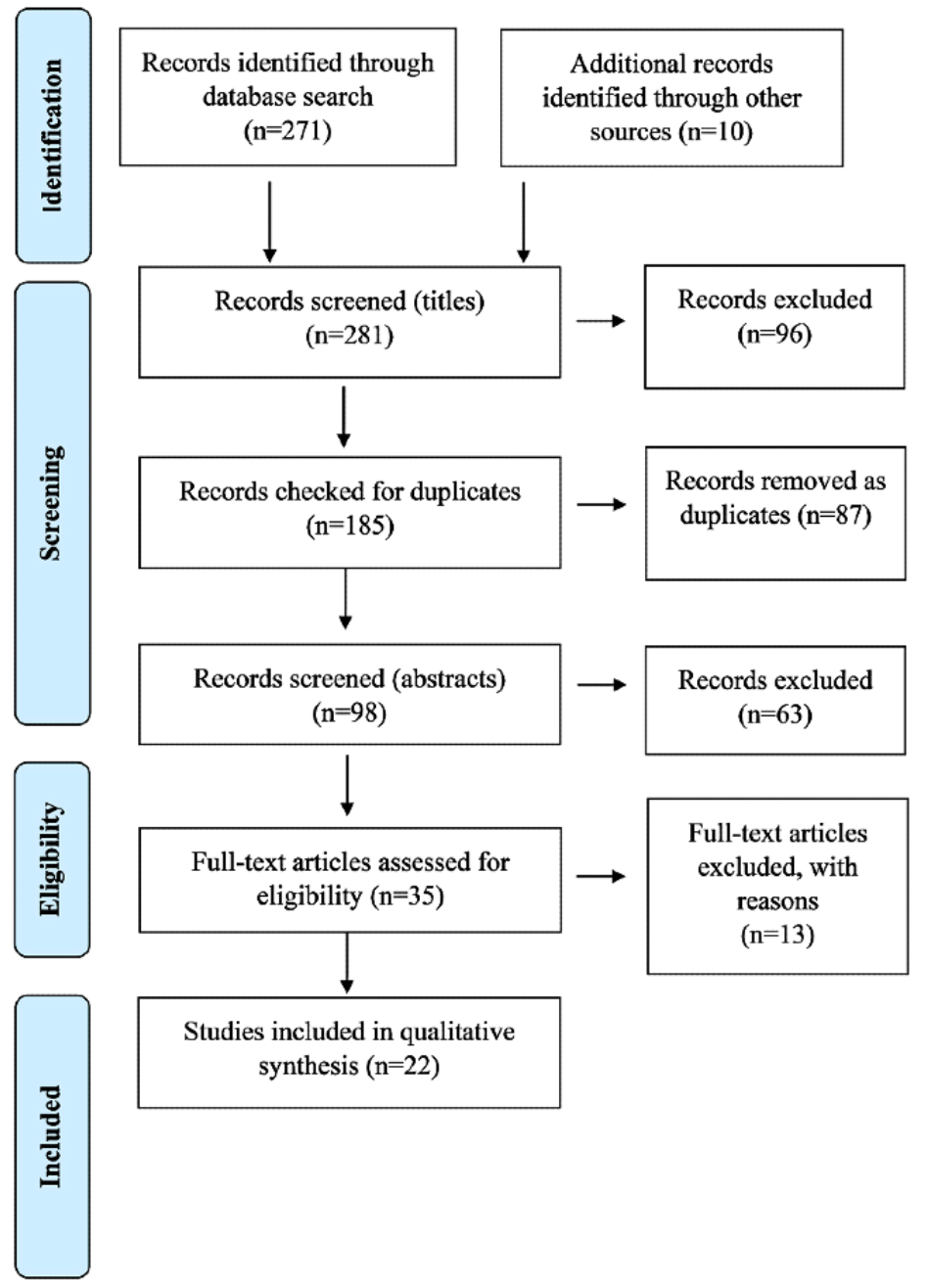


Table 2. Information extracted and collected from the selected papers.

\begin{tabular}{|c|c|c|c|c|c|c|}
\hline \multirow{2}{*}{$\begin{array}{l}\text { Study first } \\
\text { author, year }\end{array}$} & \multirow[t]{2}{*}{ Location } & \multicolumn{2}{|l|}{ Use cases and fields } & \multicolumn{2}{|c|}{ Usability and reasons for using blockchain } & \multirow[t]{2}{*}{ Technology } \\
\hline & & Application area & Description & $\begin{array}{l}\text { Simplified classi- } \\
\text { fication }\end{array}$ & Description & \\
\hline $\begin{array}{l}\text { Maslove, } \\
2018 \text { [14] }\end{array}$ & $\begin{array}{l}\text { Kingston, Cana- } \\
\text { da }\end{array}$ & $\begin{array}{l}\text { Biomedical re- } \\
\text { search and educa- } \\
\text { tion (ie, clinical tri- } \\
\text { als) }\end{array}$ & $\begin{array}{l}\text { Development of a system } \\
\text { that uses a web-based in- } \\
\text { terface to allow users to } \\
\text { run trial-related smart } \\
\text { contracts on an Ethereum } \\
\text { network }\end{array}$ & Data integrity & $\begin{array}{l}\text { Enabling of clinical trials data } \\
\text { management; functions allow } \\
\text { patients to grant researchers } \\
\text { access to their data and allow } \\
\text { researchers to submit queries } \\
\text { for data that are stored off- } \\
\text { chain }\end{array}$ & Ethereum \\
\hline $\begin{array}{l}\text { Cunning- } \\
\text { ham, } 2017 \\
{[18]}\end{array}$ & $\begin{array}{l}\text { The Nether- } \\
\text { lands }\end{array}$ & $\begin{array}{l}\text { Electronic medical } \\
\text { record (EMR) }\end{array}$ & $\begin{array}{l}\text { A system that uses smart } \\
\text { contract-based Ethereum } \\
\text { blockchain technology to } \\
\text { operate in a verifiably } \\
\text { secure, trustless, and } \\
\text { openly auditable environ- } \\
\text { ment }\end{array}$ & Access control & $\begin{array}{l}\text { Improvement of the uptake and } \\
\text { acceptance of medical informat- } \\
\text { ics platforms where patients } \\
\text { directly control medical data in } \\
\text { an open and secure manner }\end{array}$ & Ethereum \\
\hline $\begin{array}{l}\text { Nugent, } \\
2016 \text { [29] }\end{array}$ & $\begin{array}{l}\text { London, the } \\
\text { United King- } \\
\text { dom }\end{array}$ & $\begin{array}{l}\text { Biomedical re- } \\
\text { search and educa- } \\
\text { tion (ie, clinical tri- } \\
\text { als) }\end{array}$ & $\begin{array}{l}\text { A system that uses smart } \\
\text { contracts, which enhance } \\
\text { the trust in the data and } \\
\text { clinical trials; this re- } \\
\text { duces patient risk and fi- } \\
\text { nancial strain in health } \\
\text { care by allowing better- } \\
\text { informed decisions to be } \\
\text { made by medical profes- } \\
\text { sionals }\end{array}$ & $\begin{array}{l}\text { Data integrity } \\
\text { and logging }\end{array}$ & $\begin{array}{l}\text { Improvement of data transparen- } \\
\text { cy in clinical trials and im- } \\
\text { mutable records of trial history, } \\
\text { which act as trusted administra- } \\
\text { tors; tamper-resistant character- } \\
\text { istics of blockchain prevent all } \\
\text { forms of manipulation; mainly } \\
\text { used for complex clinical trial } \\
\text { management }\end{array}$ & Ethereum \\
\hline $\begin{array}{l}\text { Benchoufi, } \\
2017 \text { [15] }\end{array}$ & Paris, France & $\begin{array}{l}\text { Biomedical re- } \\
\text { search and educa- } \\
\text { tion (ie, clinical tri- } \\
\text { als) }\end{array}$ & $\begin{array}{l}\text { A system with time- } \\
\text { stamping of each pa- } \\
\text { tient's consent using } \\
\text { blockchain technology in } \\
\text { a securely unfalsifiable } \\
\text { and transparent way }\end{array}$ & $\begin{array}{l}\text { Nonrepudiation, } \\
\text { logging, and data } \\
\text { versioning }\end{array}$ & $\begin{array}{l}\text { All consent-related data on the } \\
\text { blockchain enhance security, } \\
\text { reliability, and transparency } \\
\text { and could be a consistent step } \\
\text { toward reproducibility }\end{array}$ & $\mathrm{N} / \mathrm{A}^{\mathrm{a}}$ \\
\hline $\begin{array}{l}\text { Ichikawa, } \\
2017 \text { [16] }\end{array}$ & Tokyo, Japan & $\begin{array}{l}\text { Remote patient } \\
\text { monitoring (ie, } \\
\text { mobile health } \\
\text { [mHealth] })\end{array}$ & $\begin{array}{l}\text { Development of a smart- } \\
\text { phone app with } \\
\text { blockchain technology to } \\
\text { provide an mHealth sys- } \\
\text { tem for cognitive behav- } \\
\text { ioral therapy for insom- } \\
\text { nia }\end{array}$ & Data integrity & $\begin{array}{l}\text { Establishment of accessibility } \\
\text { and transparency of data with- } \\
\text { out the third party by incorpo- } \\
\text { rating blockchain technology } \\
\text { into mHealth; blockchain also } \\
\text { serves as a tamperproof system } \\
\text { for mHealth }\end{array}$ & $\begin{array}{l}\text { Hyperledger } \\
\text { Fabric }\end{array}$ \\
\hline $\begin{array}{l}\text { Cichosz, } \\
2018[25]\end{array}$ & $\begin{array}{l}\text { Aalborg, Den- } \\
\text { mark }\end{array}$ & $\begin{array}{l}\text { EMR (ie, health } \\
\text { care data) }\end{array}$ & $\begin{array}{l}\text { Development of a plat- } \\
\text { form using the New } \\
\text { Economy Movement } \\
\text { (NEM) multi-signature } \\
\text { blockchain contracts to } \\
\text { access data management, } \\
\text { sharing, and encryption }\end{array}$ & $\begin{array}{l}\text { Access control } \\
\text { and data integrity }\end{array}$ & $\begin{array}{l}\text { Improvement in privacy and } \\
\text { diabetes data management, } \\
\text { where patients have access to } \\
\text { control and share their own data }\end{array}$ & NEM \\
\hline $\begin{array}{l}\text { Omar, } 2019 \\
{[26]}\end{array}$ & $\begin{array}{l}\text { The United } \\
\text { States }\end{array}$ & EMR & $\begin{array}{l}\text { Development of a pa- } \\
\text { tient-centric health care } \\
\text { data management system } \\
\text { using blockchain technol- } \\
\text { ogy as storage, which en- } \\
\text { hances privacy }\end{array}$ & Data integrity & $\begin{array}{l}\text { Patients will have overall con- } \\
\text { trol over their data; Med- } \\
\text { iBchain increases patients' in- } \\
\text { terest in EMRs or electronic } \\
\text { health records and enhances } \\
\text { accountability, integrity, } \\
\text { pseudonymity, security, and } \\
\text { privacy }\end{array}$ & N/A \\
\hline
\end{tabular}




\begin{tabular}{|c|c|c|c|c|c|c|}
\hline \multirow{2}{*}{$\begin{array}{l}\text { Study first } \\
\text { author, year }\end{array}$} & \multirow[t]{2}{*}{ Location } & \multicolumn{2}{|l|}{ Use cases and fields } & \multicolumn{2}{|c|}{ Usability and reasons for using blockchain } & \multirow[t]{2}{*}{ Technology } \\
\hline & & Application area & Description & $\begin{array}{l}\text { Simplified classi- } \\
\text { fication }\end{array}$ & Description & \\
\hline $\begin{array}{l}\text { Liang, } 2017 \\
{[30]}\end{array}$ & $\begin{array}{l}\text { Norfolk, Eng- } \\
\text { land }\end{array}$ & $\begin{array}{l}\text { Remote patient } \\
\text { monitoring }\end{array}$ & $\begin{array}{l}\text { Development of an } \\
\text { mHealth care system for } \\
\text { personal health data col- } \\
\text { lection, sharing, and col- } \\
\text { laboration between indi- } \\
\text { viduals, health care } \\
\text { providers, and insurance } \\
\text { companies, and its imple- } \\
\text { mentation in a distributed } \\
\text { and trustless way }\end{array}$ & $\begin{array}{l}\text { Data integrity, } \\
\text { access control, } \\
\text { and logging }\end{array}$ & $\begin{array}{l}\text { Improvement of personal health } \\
\text { data collection, sharing, valida- } \\
\text { tion, protection, and integrity } \\
\text { and health care collaboration; } \\
\text { this system ensures the scalabil- } \\
\text { ity and efficiency of the data } \\
\text { process by handling a large data } \\
\text { set at low latency }\end{array}$ & $\begin{array}{l}\text { Hyperledger } \\
\text { Fabric }\end{array}$ \\
\hline $\begin{array}{l}\text { Bocek, } 2017 \\
{[32]}\end{array}$ & $\begin{array}{l}\text { Zurich, Switzer- } \\
\text { land }\end{array}$ & $\begin{array}{l}\text { Pharmaceutical } \\
\text { supply chain (ie, } \\
\text { ambient tempera- } \\
\text { ture) }\end{array}$ & $\begin{array}{l}\text { Implementation of sensor } \\
\text { devices using blockchain } \\
\text { technology to enhance } \\
\text { data immutability and } \\
\text { public accessibility of } \\
\text { temperature records }\end{array}$ & Logging & $\begin{array}{l}\text { This system can be evaluated } \\
\text { automatically, and the stored } \\
\text { data are tamperproof with } \\
\text { Ethereum, which can be used } \\
\text { at a low cost }\end{array}$ & Ethereum \\
\hline $\begin{array}{l}\text { Mendes, } \\
2018 \text { [22] }\end{array}$ & Évora, Portugal & EMR & $\begin{array}{l}\text { Development of a system } \\
\text { with raw blockchain with } \\
\text { Hyperledger Fabric by } \\
\text { DLA }\end{array}$ & Data integrity & $\begin{array}{l}\text { While consuming low computa- } \\
\text { tional power, it enhances tam- } \\
\text { perproof, fair, and democratic } \\
\text { maintenance of the ledger }\end{array}$ & $\begin{array}{l}\text { Hyperledger } \\
\text { Fabric }\end{array}$ \\
\hline $\mathrm{Li}, 2018[20]$ & Beijing, China & $\begin{array}{l}\text { EMR (ie, health } \\
\text { record) }\end{array}$ & $\begin{array}{l}\text { Development of a novel } \\
\text { blockchain-based data } \\
\text { preservation system } \\
\text { based on the real-world } \\
\text { blockchain-based plat- } \\
\text { form, and its implementa- } \\
\text { tion for medical data }\end{array}$ & Data integrity & $\begin{array}{l}\text { Preservation of important data } \\
\text { in perpetuity and verification } \\
\text { of data originality; illegal oper- } \\
\text { ation of the data is detected, } \\
\text { and the user is notified on time }\end{array}$ & Ethereum \\
\hline $\begin{array}{l}\text { Azaria, } 2016 \\
{[17]}\end{array}$ & $\begin{array}{l}\text { The United } \\
\text { States }\end{array}$ & $\begin{array}{l}\text { EMR (ie, health } \\
\text { record) }\end{array}$ & $\begin{array}{l}\text { Development of a decen- } \\
\text { tralized record manage- } \\
\text { ment system using } \\
\text { blockchain technology to } \\
\text { handle EMRs }\end{array}$ & $\begin{array}{l}\text { Logging and ac- } \\
\text { cess control }\end{array}$ & $\begin{array}{l}\text { The system becomes more } \\
\text { convenient and adaptable in its } \\
\text { management of authentication, } \\
\text { confidentiality, accountability, } \\
\text { and data sharing }\end{array}$ & Ethereum \\
\hline $\begin{array}{l}\text { Zhou, } 2018 \\
\text { [33] }\end{array}$ & Beijing, China & $\begin{array}{l}\text { Health insurance } \\
\text { claims }\end{array}$ & $\begin{array}{l}\text { Development of a } \\
\text { blockchain-based medi- } \\
\text { cal insurance storage } \\
\text { system, MIStore; this } \\
\text { helps insurance compa- } \\
\text { nies obtain patients' } \\
\text { medical spending } \\
\text { records, which are al- } \\
\text { ways confidential }\end{array}$ & $\begin{array}{l}\text { Data integrity } \\
\text { and logging }\end{array}$ & $\begin{array}{l}\text { The system provides decentral- } \\
\text { ization and tamper resistance; } \\
\text { this gives users high credibility } \\
\text { and record-nodes, which help } \\
\text { users verify publicly verifiable } \\
\text { data }\end{array}$ & Ethereum \\
\hline $\begin{array}{l}\text { Angeletti, } \\
2017 \text { [27] }\end{array}$ & Rome, Italy & $\begin{array}{l}\text { Biomedical re- } \\
\text { search and educa- } \\
\text { tion (ie, clinical tri- } \\
\text { als) }\end{array}$ & $\begin{array}{l}\text { Presentation of a digital } \\
\text { health application en- } \\
\text { abling clinical trials re- } \\
\text { cruitment using Internet } \\
\text { of Things data; using } \\
\text { Ethereum, a proof of } \\
\text { concept was implement- } \\
\text { ed, and the application's } \\
\text { performance was studied } \\
\text { in a real-world evaluation }\end{array}$ & $\begin{array}{l}\text { Data integrity } \\
\text { and access con- } \\
\text { trol }\end{array}$ & $\begin{array}{l}\text { The clinical research institute } \\
\text { can be guaranteed that it is ac- } \\
\text { quiring useful and original data; } \\
\text { until an agreement is reached, } \\
\text { the individual can keep person- } \\
\text { al data private }\end{array}$ & Ethereum \\
\hline
\end{tabular}




\begin{tabular}{|c|c|c|c|c|c|c|}
\hline \multirow{2}{*}{$\begin{array}{l}\text { Study first } \\
\text { author, year }\end{array}$} & \multirow[t]{2}{*}{ Location } & \multicolumn{2}{|c|}{ Use cases and fields } & \multicolumn{2}{|c|}{ Usability and reasons for using blockchain } & \multirow[t]{2}{*}{ Technology } \\
\hline & & Application area & Description & $\begin{array}{l}\text { Simplified classi- } \\
\text { fication }\end{array}$ & Description & \\
\hline $\begin{array}{l}\text { Saravanan, } \\
2017 \text { [31] }\end{array}$ & Chennai, India & $\begin{array}{l}\text { Remote patient } \\
\text { monitoring }\end{array}$ & $\begin{array}{l}\text { Implementation of a new } \\
\text { health care paradigm } \\
\left(\mathrm{SMEAD}^{\mathrm{b}}\right) \text { to aid diabet- } \\
\text { ic patients via develop- } \\
\text { ment of an end-to-end } \\
\text { secured system; imple- } \\
\text { mentation of a } \\
\text { blockchain-based disrup- } \\
\text { tive technology to facili- } \\
\text { tate cryptographic securi- } \\
\text { ty and formalized data } \\
\text { access through smart } \\
\text { contracts }\end{array}$ & Access control & $\begin{array}{l}\text { The system aids in data storage } \\
\text { for millions of patients, and } \\
\text { analysis was performed in real } \\
\text { time, which promotes an evi- } \\
\text { dence-based medicine system } \\
\text { with privacy and security con- } \\
\text { cerns }\end{array}$ & Ethereum \\
\hline $\begin{array}{l}\text { Zhang, } 2018 \\
{[24]}\end{array}$ & $\begin{array}{l}\text { The United } \\
\text { States }\end{array}$ & $\begin{array}{l}\text { EMR (ie, health } \\
\text { record) }\end{array}$ & $\begin{array}{l}\text { Development of a system } \\
\text { to support collaborative } \\
\text { clinical decision-making } \\
\text { via a remote tumor board } \\
\text { case study }\end{array}$ & $\begin{array}{l}\text { Access control } \\
\text { and data integrity }\end{array}$ & $\begin{array}{l}\text { Improvement of security, trust, } \\
\text { and scalable data sharing, } \\
\text { which is important for collabo- } \\
\text { rative clinical decision-making; } \\
\text { also results in greater data } \\
\text { readability }\end{array}$ & Ethereum \\
\hline $\begin{array}{l}\text { Fan, } 2018 \\
{[19]}\end{array}$ & China & $\begin{array}{l}\text { EMR (ie, health } \\
\text { record) }\end{array}$ & $\begin{array}{l}\text { Development of a } \\
\text { blockchain-based infor- } \\
\text { mation management sys- } \\
\text { tem, MedBlock, to han- } \\
\text { dle patients' information; } \\
\text { this allows for efficient } \\
\text { EMR access and re- } \\
\text { trieval, exhibiting high } \\
\text { information security }\end{array}$ & Access control & $\begin{array}{l}\text { Patients can easily access the } \\
\text { EMRs of different hospitals; } \\
\text { data sharing via blockchain } \\
\text { helps the hospital get a full his- } \\
\text { tory of patients' medical history } \\
\text { before consultations are carried } \\
\text { out }\end{array}$ & $\mathrm{N} / \mathrm{A}$ \\
\hline $\begin{array}{l}\text { Liu, } 2018 \\
{[21]}\end{array}$ & China & EMR & $\begin{array}{l}\text { Implementation of } \\
\text { blockchain-based priva- } \\
\text { cy-preserving data shar- } \\
\text { ing for EMRs }\end{array}$ & Access control & $\begin{array}{l}\text { The EMRs cannot be modified } \\
\text { arbitrarily, which leads to re- } \\
\text { duced medical data leakage; } \\
\text { security analysis shows that this } \\
\text { system is a secure and effective } \\
\text { way to realize data sharing for } \\
\text { EMRs }\end{array}$ & N/A \\
\hline $\begin{array}{l}\text { Nagasubra- } \\
\text { manian, } \\
2018[23]\end{array}$ & $\begin{array}{l}\text { London, the } \\
\text { United King- } \\
\text { dom }\end{array}$ & EMR & $\begin{array}{l}\text { Ensuring secrecy of digi- } \\
\text { tal signatures and authen- } \\
\text { tication by using keyless } \\
\text { signature infrastructure } \\
\text { in the system }\end{array}$ & Access control & $\begin{array}{l}\text { The system ensures data trans- } \\
\text { parency, privacy, confidentiali- } \\
\text { ty, and verification of data }\end{array}$ & N/A \\
\hline $\begin{array}{l}\text { Kotsiuba, } \\
2018[34]\end{array}$ & Ukraine & $\begin{array}{l}\text { Health care data } \\
\text { analytics }\end{array}$ & $\begin{array}{l}\text { Implementation of a de- } \\
\text { centralized system with } \\
\text { blockchain technology } \\
\text { that protects the confiden- } \\
\text { tiality of medical data; } \\
\text { patients receive a person- } \\
\text { al data monitoring tool, } \\
\text { allowing them to partici- } \\
\text { pate in accelerating med- } \\
\text { ical analytics }\end{array}$ & Data integrity & $\begin{array}{l}\text { Enhancement of medical data } \\
\text { safety, extension of the base of } \\
\text { clinical data collection, and } \\
\text { creation of an effective shared } \\
\text { health infrastructure }\end{array}$ & N/A \\
\hline $\begin{array}{l}\text { Talukder, } \\
2018[35]\end{array}$ & $\begin{array}{l}\text { The United } \\
\text { States }\end{array}$ & Others & $\begin{array}{l}\text { Implementation of an } \\
\text { Ethereum-based Proof of } \\
\text { Disease consensus proto- } \\
\text { col to enhance the accura- } \\
\text { cy of transactions and } \\
\text { eliminate medical errors }\end{array}$ & $\begin{array}{l}\text { Access control } \\
\text { and data integrity }\end{array}$ & $\begin{array}{l}\text { Aids in achieving all the com- } \\
\text { plex needs of P6 (participatory, } \\
\text { personalized, proactive, preven- } \\
\text { tive, predictive, and precision) } \\
\text { medicine and decreases disease } \\
\text { burden }\end{array}$ & Ethereum \\
\hline
\end{tabular}

${ }^{\mathrm{a}}$ N/A: not applicable: the technology was not reported in this paper.

${ }^{\mathrm{b}}$ SMEAD: Secured Mobile-Enabled Assisting Device for Diabetics. 


\section{Publication Year, Publication Type, and Geographical} Distribution

All the selected papers were published since 2016. This indicates that blockchain technology in health care settings is very new. It is noted that from the 22 selected papers, the majority $(\mathrm{n}=12$, $55 \%)$ were published in 2018, $7(32 \%)$ papers were published in $2017,2(9 \%)$ papers were published in 2016 , and $1(5 \%)$ paper was published in 2019.

The locations (ie, countries) of the institutions of the authors of the selected primary papers were used to distinguish the geographical distribution of the research community members who were involved in the research. If a paper had authors from different countries, the country of the corresponding author was used. It is noted that the authors, universities, and companies in the United States and China were leading, having 4 (18\%) papers each. This was followed by the United Kingdom with 3 (14\%) papers and the Netherlands with $2(9 \%)$ papers. The rest of the countries, namely Ukraine, India, Italy, Portugal, Switzerland, Denmark, Japan, France, and Canada, contributed $1(5 \%)$ paper each. This geographical distribution of the 22 selected papers indicates that blockchain technology in the health care sector has gathered research interest around the world.

The channels where the papers were published determined the publication type. The two publication types included in this systematic review were conferences and journals. The majority $(n=15,68 \%)$ of the 22 selected primary papers were published in journals, while 7 (32\%) were published as conference proceedings.

The 22 selected primary papers were studied, and the data or keywords related to this systematic review's question were extracted. A classification scheme was constructed based on the iterative identification of data, charting keywords extracted from the selected papers. The papers were then sorted into identified categories.

Each of the selected primary papers addressed one or more different aspects of the use cases of blockchain technology in the health care sector. Therefore, the identified use cases were used to further classify the selected papers. Out of 22 selected papers, $10(45 \%)$ addressed the application of blockchain in the management of EMRs, 5 (23\%) addressed the use of blockchain technology in biomedical research and education, and 3 (14\%) demonstrated the use of blockchain technology in remote patient monitoring. The remaining papers addressed the use of blockchain technology in drug or pharmaceutical supply chains $(n=1,5 \%)$, health insurance claims $(n=1,5 \%)$, health data analytics $(n=1,5 \%)$, and other applications $(n=1,5 \%)$.

In the selected primary papers, blockchain was implemented in the real health care environment to address several information security components. The use of blockchain technology or the main reason it was implemented in health care was classified.
From this data, it was noted that each of the selected primary papers addressed one or more reasons, out of a total of 34 reasons or benefits, for using blockchain technology in health care. Most papers addressed the application of blockchain in health care for data integrity $(14 / 34,41 \%)$. The next largest purpose of blockchain application was access control, which contributed 11 out of $34(32 \%)$ reasons in the papers. Meanwhile, data logging was addressed $6(18 \%)$ times, data versioning was addressed $2(6 \%)$ times, and nonrepudiation was addressed $1(3 \%)$ time.

The setting of the studies, specifically the type of hospital used for the implementation of blockchain technology, was analyzed among the 22 selected papers. Only 3 out of 22 (14\%) papers gave the name of hospital where the study was carried out. Maslove et al [14] implemented a blockchain-based smart contract at Kingston General Hospital, Canada, to study how blockchain technology could be used in clinical trial data management, which could enhance data integrity. Another study on clinical trials data management was conducted by Benchoufi et al [15] at Hospital Hôtel Dieu, Paris, France, which looked at whether the implementation of blockchain could enhance the transparency and traceability of clinical trial consent, thereby benefitting both patients and researchers. Ichikawa et al [16] conducted their study at the Institute of Neuropsychiatry, Seiwa Hospital, Tokyo, Japan, using blockchain technology to implement a tamper-resistant mobile health (mHealth) system, which could enhance both data transparency and accessibility without the involvement of a third party.

Information regarding the blockchain platform that was used was gathered from the 22 selected papers. Ethereum was the most commonly used blockchain platform $(n=12,55 \%)$, followed by Hyperledger Fabric $(n=3,14 \%)$, while the least used platform was the New Economy Movement (NEM) blockchain platform $(n=1,5 \%)$. The rest of the studies did not state which blockchain platform was used.

\section{Literature Quality Analysis}

The final and crucial part of this systematic review involved reviewers scoring the 22 papers to evaluate their quality and the relevance of the blockchain usage. The scoring results are shown in Table 3 [14-35]. These show a greater quality of average overall scores among 15 journal papers (mean score $81.0 \%$, SD 5.8\%) compared to 7 conference papers (mean score $77.1 \%$, SD $5.9 \%)$. Out of the 22 papers, $3(14 \%)$ high-quality papers, $9(41 \%)$ moderate-quality papers, and $10(45 \%)$ low-quality papers were identified. It is noted that no published conference papers from January to September 2019 were found or included in this study.

The $2(9 \%)$ papers published in 2016 each had a relatively high average overall score. In 2017, the average overall score of the papers was $80 \%$, which was slightly lower than that of 2016 . This dropped to $78 \%$ in 2018 and rose again to $80 \%$ in 2019. 
Table 3. Summary of scores for measuring quality of the publications.

\begin{tabular}{|c|c|c|c|c|c|c|c|c|}
\hline \multirow[t]{2}{*}{ Study first author, year } & \multirow[t]{2}{*}{ Type of publication } & \multicolumn{4}{|c|}{ Points per question $(\mathrm{Q})^{\mathrm{a}}$} & \multirow{2}{*}{$\begin{array}{l}\text { Sum of } \\
\text { scores for } \\
\text { Q2-Q4 }\end{array}$} & \multirow{2}{*}{$\begin{array}{l}\text { Overall score for } \\
\text { Q1-Q4 (\%), mean } \\
\text { (SD) }\end{array}$} & \multirow[t]{2}{*}{ Quality of paper ${ }^{b}$} \\
\hline & & Q1 & Q2 & Q3 & Q4 & & & \\
\hline Maslove, 2018 [14] & Journal & 4 & 3 & 3 & 4 & 10 & $90.0(0.5)$ & High \\
\hline Benchoufi, 2017 [15] & Journal & 4 & 3 & 2 & 3 & 8 & $80.0(0.7)$ & Moderate \\
\hline Ichikawa, 2017 [16] & Conference proceeding & 4 & 4 & 2 & 3 & 9 & $85.0(0.8)$ & Moderate \\
\hline Azaria, 2016 [17] & Journal & 4 & 3 & 2 & 3 & 8 & $80.0(0.7)$ & Moderate \\
\hline Cunningham, 2017 [18] & Journal & 4 & 3 & 2 & 4 & 9 & $85.0(0.8)$ & Moderate \\
\hline Fan, 2018 [19] & Journal & 4 & 3 & 1 & 3 & 7 & $75.0(1.1)$ & Low \\
\hline Li, 2018 [20] & Conference proceeding & 4 & 3 & 2 & 4 & 9 & $85.0(0.8)$ & Moderate \\
\hline Liu, 2018 [21] & Journal & 4 & 3 & 2 & 2 & 7 & $75.0(0.8)$ & Low \\
\hline Mendes, 2018 [22] & Journal & 4 & 3 & 1 & 3 & 7 & $75.0(1.1)$ & Low \\
\hline Nagasubramanian, 2018 [23] & Journal & 4 & 3 & 2 & 3 & 8 & $80.0(0.7)$ & Moderate \\
\hline Zhang, 2018 [24] & Journal & 4 & 3 & 1 & 3 & 7 & $75.0(1.1)$ & Low \\
\hline Cichosz, 2018 [25] & Journal & 4 & 4 & 2 & 3 & 9 & $85.0(0.8)$ & Moderate \\
\hline Omar, 2019 [26] & Conference proceeding & 4 & 3 & 1 & 3 & 7 & $75.0(1.1)$ & Low \\
\hline Angeletti, 2017 [27] & Journal & 4 & 4 & 2 & 4 & 10 & $90.0(0.9)$ & High \\
\hline Kleinaki, 2018 [28] & Journal & 4 & 3 & 1 & 3 & 7 & $75.0(1.1)$ & Low \\
\hline Nugent, 2016 [29] & Journal & 4 & 4 & 2 & 4 & 10 & $90.0(0.9)$ & High \\
\hline Liang, 2017 [30] & Conference proceeding & 4 & 3 & 1 & 3 & 7 & $75.0(1.1)$ & Low \\
\hline Saravanan, 2017 [31] & Journal & 4 & 3 & 1 & 3 & 7 & $75.0(1.1)$ & Low \\
\hline Bocek, 2017 [32] & Journal & 4 & 4 & 1 & 4 & 9 & $85.0(1.3)$ & Moderate \\
\hline Zhou, 2018 [33] & Conference proceeding & 4 & 4 & 1 & 3 & 8 & $80.0(1.2)$ & Moderate \\
\hline Kotsiuba, 2018 [34] & Conference proceeding & 4 & 3 & 1 & 2 & 6 & $70.0(1.1)$ & Low \\
\hline Talukder, 2018 [35] & Conference proceeding & 4 & 3 & 0 & 3 & 6 & $70.0(1.5)$ & Low \\
\hline
\end{tabular}

${ }^{\text {a }}$ Two reviewers assessed each query from Q1 to Q4, based on a 5-point ordinal scale ranging from 0 to 4 , where 0 indicates the lowest level (criterion was addressed very poorly or not at all) and 4 indicates the highest level (criterion was exceptional).

${ }^{b}$ An overall score of $\geq 90 \%$ indicates a high-quality paper; an overall score of $80 \%-89 \%$ indicates a moderate-quality paper; an overall score $\leq 79 \%$ indicates a low-quality paper.

\section{Discussion}

\section{Identified Themes}

The identified themes are summarized in Figure 2. 
Figure 2. The uses of blockchain technology in the health care sector.
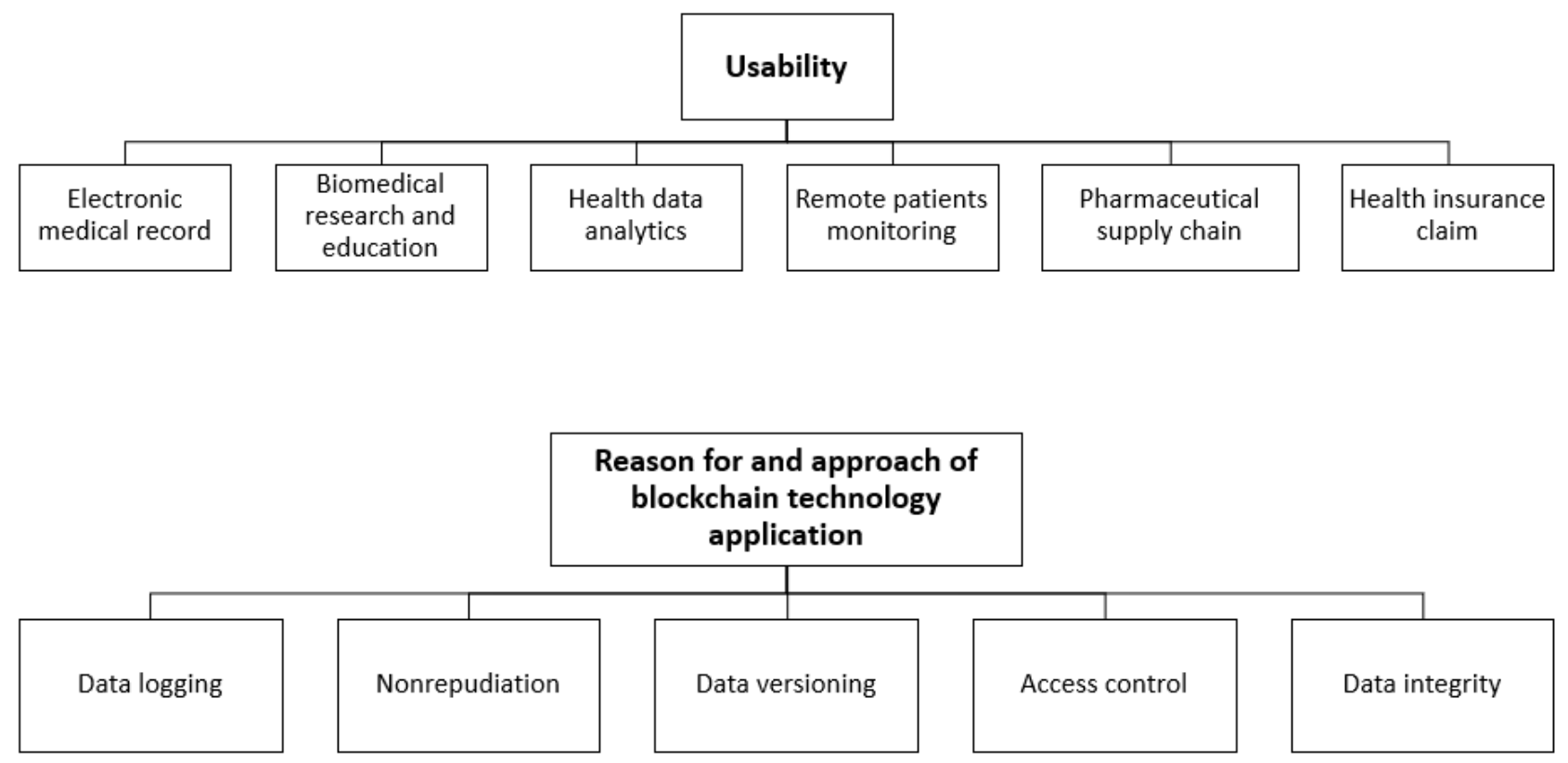

\section{The Use of Blockchain Technology in Real Health Care Environments}

The results from this systematic review show that the majority of the research regarding blockchain technology in health care environments was focused on the management of EMRs, followed by biomedical research and education, remote patient monitoring, pharmaceutical supply chains, health insurance claims, health data analytics, and other potential areas.

\section{Electronic Medical Records}

Out of 22 selected papers, $10(45 \%)$ concentrated on the management of EMRs. EMRs, similar to EHRs or personal health records, involve electronic modeling, storage, and management of patients' personal, medical, or health-related data. Traditionally, different systems have been used to store patients' records separately across different service providers, where the service providers have control over the records, which may limit data sharing with other health care stakeholders.

The application of blockchain in the management of EHRs will make data sharing among health care stakeholders easier, more transparent, and more trustworthy, and patients will have control over their own data. This is because the characteristics of blockchain technology, such as decentralization, immutability, data provenance, reliability, robustness, smart contracts, security, and privacy, make it suitable for the management and storage of patient EHRs [18].

Azaria et al [17] presented MedRec, which is a project from the MIT (Massachusetts Institute of Technology) Media Lab and Beth Israel Deaconess Medical Center that uses a blockchain-based platform to give patients access to their own data through some access permissions built into the blockchain. The patient may decide to grant access to their EHRs to any third party, which may reduce their paperwork, given that patients normally have to carry a bundle of papers with them when they seek out different health care providers for consultation. With blockchain technology, regardless of the time and institution, health care providers can easily gain access to all of a patient's medical data. Patients become more committed to their own health care because they are directly involved in the management of their health records through blockchain technology.

The second application that would integrate EMRs is blockchain-based privacy-preserving data sharing (BPDS), which was developed by Liu et al [21]. This uses the Ethereum blockchain platform, which reduces the risk of medical data leakage and secures data sharing in health care.

Fan et al [19] developed MedBlock, a blockchain-based information management system that is implemented in health care to enhance efficiency and secure electronic medical data sharing using blockchain. Another blockchain-based EMR is FHIRChain [24], which encapsulates the Health Level Seven Fast Healthcare Interoperability Resources (FHIR) standard for shared clinical data. Zhang et al [24] used blockchain technology via the FHIRChain-based decentralized app to share clinical data that focused on health care record management and digital health identities to verify participants for remote cancer care in a case study of collaborative decision-making [24]. Cichosz et al [25] proposed NEM multi-signature blockchain contracts to be used for the management and sharing of medical data of diabetes patients, which aimed to achieve access control and data privacy.

Li et al [20] presented a medical data preservation system based on the real-world blockchain platform Ethereum, which provides a trustworthy storage solution to ensure the primitiveness and verifiability of stored data. Mendes et al [22] presented a Smart Ambient Assisted Living environment, which uses blockchain technology to enhance data privacy and cognitive security in the health care sector. As noted above, out of the 22 included papers, $3(14 \%)$ were high-quality papers, $9(41 \%)$ were moderate-quality papers, and $10(45 \%)$ were low-quality papers. 
Therefore, the conclusions made are convincing based on the high or moderate quality of a high percentage of papers.

\section{Biomedical Research and Education: Clinical Research}

A total of $23 \%(5 / 22)$ of the selected papers in this study indicated that blockchain could be applied in biomedical research and education fields. Blockchain technology has been used extensively in biomedical research and education to preserve data privacy, integrity, sharing, record sharing, and record keeping, especially in clinical trials [23]. Nugent et al [29] presented blockchain smart contracts that prevent falsification of data and underreporting of unwanted results of clinical research, which enhances trust in the data and clinical trials.

Angeletti et al [27] proposed a proof-of-concept implementation of consent traceability in clinical trials using Ethereum to secure and ensure unfalsifiable data. Every piece of data or consent included in the blockchain system is time-stamped and publicly transparent. This is achieved through cryptographic validation. All plans, consent, protocols, and possible outcomes can be stored on blockchain even before the inception of clinical trials, which prevents any corruption and undesirable study results.

Kleinaki et al [28] presented a blockchain-based notarization service that uses smart contracts to seal biomedical database queries and the respective results, which ensures data transparency. Maslove et al [14] proposed BlockTrial, a web-based interface system that allow users to run trial-related smart contracts on the Ethereum network in clinical data management, thereby enhancing the reliability and transparency of complex data in clinical trials. The tamperproof characteristics of blockchain prevents the manipulation of data in clinical trials.

\section{Remote Patient Monitoring}

Remote patient monitoring was another blockchain use case in the health care sector. Generally, remote patient monitoring includes the gathering of biomedical data from the body and mobile devices to enable the monitoring of patient status remotely outside of traditional health care environments, such as hospitals.

Liang et al [30] presented a Hyperledger-based implementation of blockchain in mHealth that enables data collection and sharing between health care stakeholders, ensuring both data transparency and accessibility. Saravanan et al [31] proposed an end-to-end secured system, a new health care paradigm (ie, Secured Mobile-Enabled Assisting Device for Diabetics), through smart contracts to facilitate cryptographic security and formalized data access in which to monitor diabetes patients. The author stated that blockchain was engaged in a mobile-enabled assisting device that was developed to monitor diabetes patients. Ichikawa et al [16] presented a tamper-resistant mHealth system using blockchain technology where a mobile device is used to gather EMRs, which are then sent to the blockchain-based Hyperledger Fabric network to ensure secure management of the data.

Cichosz et al [25] proposed NEM multi-signature blockchain contracts for assisting diabetes patients in monitoring and transmitting their vital parameters or data by sensor device to a blockchain-based platform where the data are collected, stored, and analyzed. In emergency cases, such as abnormal blood glucose levels or missing dosages, an alert via a social network, such as Facebook or WhatsApp, will be sent to the care provider. The data can be communicated continuously by using mobile devices as a gateway with blockchain technology, which could save patients from any untoward consequences.

\section{Drug or Pharmaceutical Supply Chains}

Drug or pharmaceutical supply chains are one of the use cases of blockchain technology in the health care sector, particularly health-related supply chain management. Drug or pharmaceutical supply chains involve the introduction of new drugs into the market, ensuring the safety and validity of medical products sold to end customers [32]. Blockchain has been applied in this field to allocate a safe and secure platform and to address the most common problems faced in the pharmaceutical industry, such as delivery of substandard or counterfeit medication, which may have a negative impact on patients.

In this systematic review, only 1 paper out of $22(5 \%)$ presented the implementation of a blockchain-based application for pharmaceutical supply chain management. Bocek et al [32] presented a real-world demonstration and evaluation of blockchain technology in the pharmaceutical supply chain, where ambient temperature sensors with blockchain technology were used to record temperatures at which drugs were stored and transported; such temperature measurements were immutably kept in a public blockchain for transparent inspection, which could also decrease the operational cost in a pharmaceutical supply chain.

\section{Health Insurance Claims}

Health insurance is necessary for everyone to get affordable medical treatment. Blockchain's characteristics, such as immutability, decentralization, transparency, and auditability of records, can benefit the process of health insurance claims in the health care sector. Nevertheless, only 1 paper from the $22(5 \%)$ selected primary papers focused on this application. Zhou et al [33] developed a blockchain-based medical insurance storage system that is displayed using the Ethereum blockchain platform. The medical insurance data of a patient can be encrypted and immutably stored on blockchain, which enhances credibility and eliminates the involvement of third parties in the management of patients' health insurance [33].

\section{Health Data Analytics}

Only 1 paper out of $22(5 \%)$ presented the use of blockchain technology in health data analytics. Blockchain in collaboration with other emerging technologies, such as deep- and transfer-learning techniques, was used to identify predictive analytics of health care data. Kotsiuba et al [34] stated that blockchain provides a unique opportunity to overcome the problems related to the analysis and security of medical data. Using blockchain technology, a decentralized health data ecosystem was presented that protected medical data confidentiality, produced an effective shared health infrastructure, and increased the basis of clinical data collection. 


\section{Other Functionalities}

Of the 22 selected primary papers, $1(5 \%)$ study by Talukder et al [35] included the relevant research perspective but could not be classified under any of the identified uses of blockchain. This study presented a blockchain consensus protocol that provides accurate medical decisions and reduces the disease burden by using Ethereum, based on the proof-of-disease consensus protocol. All functionalities of health data interoperability, including EMRs, patient health records, and health information exchange databases, can be achieved by this system.

\section{Reasons for the Application of Blockchain Technology in the Current Health Care System}

\section{Overview}

The main reasons $(\mathrm{N}=34)$ for the application or implementation of blockchain technology in the health care sector in this study's selected papers were identified and categorized into the following groups: data integrity $(\mathrm{n}=14,41 \%)$, access control $(\mathrm{n}=11,32 \%)$, data logging $(\mathrm{n}=6,18 \%)$, data versioning $(\mathrm{n}=2$, $6 \%)$, and nonrepudiation $(\mathrm{n}=1,3 \%)$.

\section{Data Integrity}

Data integrity is defined as the accuracy and consistency of the data or information stored in a system, which acts as an important component of information security. Data integrity was achieved by using blockchain technology in the health care sector. Li et al [20] implemented the blockchain-based platform Ethereum to maintain the originality and variability of stored data in the system while preserving user privacy. The lifelong maintenance of data in blockchain was achieved with the proof-of-primitiveness data concept, and the system can validate the data where it is identical to the original data. The data can be restored and verified through blockchain if it has been damaged.

Kotsiuba et al [34] also presented a decentralized health data system using blockchain that secures the collection and confidentially of medical or clinical data. In the study by Zhang et al [24], data integrity was enhanced by using an FHIRChain-based decentralized app, which used blockchain technology and digital health identities in remote cancer care to validate the participants in a case study of clinical data sharing. With the application of public key cryptography, this decentralized app improves the trust of participants and enables the users to share specific and structured pieces of information, rather than an entire document. Thereby, it increases the readability of data and flexibility of sharing options.

Cichosz et al [25] implemented a blockchain-based platform to enhance the management and sharing of diabetes data in an easy and secure way, which can be achieved by a decentralization of blockchain. According to a study by Omar et al [26], the integrity, security, privacy, and accountability of data in health care are achieved through a privacy-preserving platform using blockchain technology. To ensure encryption of patient data and pseudonymity, a cryptographic function was used. The decentralization of data enabled by the peer-to-peer network in blockchain technology helps to reduce cyberattacks and preserve the health care data set.

The proof-of-concept implementation of patient-facing and researcher-facing systems using blockchain technology to enhance data integrity was demonstrated by Maslove et al [14] and Angeletti et al [27]. Maslove et al [14] demonstrated that the proof-of-concept implementation using blockchain technology in clinical trials secures original personal data, and this data would not be shared publicly before an agreement is reached. In regard to the use of blockchain technology in clinical trials, the clinical research institute can also guarantee that the data obtained are authentic and useful.

Angeletti et al [27] stated that the integrity of the data collected in clinical trials was enhanced by the application of blockchain technology, specifically blockchain-based smart contracts, which act as the foundation to promote trust throughout clinical research. The proof-of-concept implementation in clinical research enhances the interaction of researchers and patients.

Blockchain in digital health technologies has also been particularly used in mHealth, which includes remote patient monitoring to ensure the safe and precise preservation of medical information to improve data integrity. Ichikawa et al [16] concluded from their study that the usage of blockchain technology in mHealth improves data transparency and accessibility without the involvement of third parties, due to the tamperproof and decentralized characteristics of blockchain technology.

\section{Access Control}

According to Azaria et al [17], access control is defined as an individual having full authority in deciding who can access their medical data, as well as when and how much of their own medical data can be accessed using blockchain technology. Access control may lead to patients' direct involvement in controlling their own medical data usage. The distributed ledger, which is one of the characteristics of blockchain technology, ensures efficient access and retrieval of EMRs [18].

Fan et al [19] used a proof of concept with an application programming interface using blockchain technology, which allows a permission system where each patient is able to view, control, and specify who can access their records.

A study by Cunningham and Ainsworth [18] found that the EMRs that included a patient's full medical history from many different hospitals could be easily accessed by the patient using a blockchain-based information management system, which enhances the outcome of treatment by avoiding the segregation of medical data from different hospitals. An access protocol was implemented that prevented unauthorized users from obtaining any sensitive data or information.

For access control and the preservation of data, Fan et al [19] used the blockchain-based platform concept with NEM multi-signature blockchain contracts, which ensured privacy control of health data. With this concept, patients are in control of their own data and have the power to decide who can access their personal data. For instance, an older adult patient could share access of their medical data with their adult child. 
According to Cichosz et al [25], patients were able to access their own medical data through smart blockchain contracts, which may lead to secure data sharing. Through BPDS, which consists of data access permission implemented by Liu et al [21], patients have full control over their medical records or data, without jeopardizing their privacy. Furthermore, a user can use patient data with permission from the patient. The owner of the data in blockchain is capable of revoking his or her access permission, in case of a violation of access rules.

According to Liu et al [21], health records that are centrally stored are more vulnerable to cyberattacks. Therefore, Nagasubramanian et al [23] presented a keyless signature infrastructure (KSI) blockchain technology for securing EHRs that ensures authentication and integrity of health records. In a KSI blockchain system, the signed data are stored and can be operated without a network connection, and no third parties are required to preserve data in this system.

Data access by health care professionals can be achieved through smart contracts of blockchain technology with cryptographic security. Using blockchain technology, Saravanan et al [31] implemented a mobile-based secure health care system that can predict a patient's diabetes status in real time. In case of emergency, the doctor can access a patient's health record and prescribe them with a suitable medication dosage using this technology system. This blockchain system is used to store data related to health care and securely connect with third parties.

\section{Data Logging}

Data logging is defined as an operation of gathering and storing information over a period of time. It allows tracking of all types of interactions, such as storage, access, or modification of data, files, or applications in a system. Data logging can be achieved by the application of blockchain technology in the health care sector.

In clinical trials, Nugent et al [29] demonstrated blockchain technology using an Ethereum smart contract to enhance the trustworthiness, reliability, and transparency of data management. The cryptographic and tamperproof characteristics of blockchain prevent all forms of manipulation and enhance the data logging of complex clinical trial data management, so more informed decisions can be made by medical professionals. An mHealth care system using blockchain technology was implemented by Liang et al [30] that ensured gathering, sharing, and collaboration of data between the health care providers and individuals in a secure way.

Bocek et al [32] stated in their study that the application of blockchain technology in pharmaceutical supply chain management ensures data logging. They demonstrated the use of an Internet of Things sensor device (modum.io AG) that uses blockchain technology to ensure the verification of compliance with quality control temperature requirements. This device was used to monitor and store the temperature of products, enhance data immutability, and facilitate public accessibility of temperature records of pharmaceutical products, especially during transportation. Data provenance was ensured using blockchain technology that can prove the origin of products in a supply chain.
Zhou et al [33] stated that blockchain technology acts as a tamperproof and decentralized technology to record data, which enhances users' trust in a health insurance system, especially with the implementation of a blockchain-based medical insurance storage system. For instance, the data about each patient's spending was stored and secured in the blockchain by the hospital, which helped the insurance company obtain information about the total amount of spending by the patient; however, third parties, including the insurance company, cannot modify or delete the data and do not have the authority to access a patient's personal medical data.

\section{Data Versioning}

Data versioning is defined as saving new copies of the data when any modification is made to the existing data. This helps to keep track of the data and ensure easy retrieval of any specific version of the respective stored data in a system. Kleinaki et al [28] implemented a blockchain-based notarization service that uses smart digital contracts to secure data in the biomedical research sector. A study by Mendes et al [22] showed that after the retrieval process, retrieved data cannot be modified, which ensures the integrity and nonrepudiation of the data. Using blockchain technology, data versioning was achieved where medical evidence of different versions of data retrieved from a biomedical database were securely stored and saved, along with content that is continually updated. In this study, this was mostly used for decision support in the health care sector.

\section{Nonrepudiation}

Nonrepudiation guarantees the validity of data in a particular health care system, which cannot not be denied by anyone and ensures the originality and integrity of data. A study by Angeletti et al [27] used blockchain technology to collect, store, and track clinical trial consent in a secure, unfalsifiable, and publicly verifiable way; this consent was originally time-stamped with the application of proof of concept, leading to the nonrepudiation of data. The authentication system ensures that the clinical trial consent is accessible and transparent for patients, while traceable for stakeholders. A single document in open format was used and accounted for the whole time-stamped consent collection process. This document cannot be corrupted and is considered a robust proof of data.

\section{Study Limitations}

One limitation of this systematic review study was that there were no published studies on the safety of blockchain technology in health care, so the safety aspect of blockchain technology cannot be reviewed. In addition, there were few papers published on the negative aspects of implementation of blockchain technology in health care. Most studies only published the positive aspects, which may have led to bias.

\section{Future Directions}

Blockchain technology is still a new technology that has not been widely implemented in the health care sector. This study can be a guide for future research, implementation, and evaluation of blockchain technology in this sector. More research should be carried out regarding the implementation of blockchain technology in real health care environments for better understanding, characterization, and evaluation. 
Researchers should also focus on carrying out research on the safety of implementing blockchain technology in health care.

\section{Conclusions}

This systematic review has presented an overview of the use and characteristics of blockchain technology in the health care sector. The findings show that blockchain technology research and application in the health care sector is still in its infancy but growing rapidly. Blockchain technology has started to develop from cryptocurrencies, such as Bitcoin, into various general-purpose technologies in many industries, including health care. According to the selected papers in this study, EMRs, biomedical research and education, remote patient monitoring, drug or pharmaceutical supply chains, health insurance claims, and health data analytics are the most common uses of blockchain technology in health care. The main reasons for the application of blockchain technology are to enhance data integrity, access control, logging, data versioning, and nonrepudiation of patient health records or other health information in health care settings.

\section{Authors' Contributions}

DE, LCM, CSL, FSB, and CST contributed to the study design, data extraction, quality assessment, analysis and interpretation of data, and drafting of the manuscript. KWG and SFY contributed to the study design, quality assessment, analysis and interpretation of data, and revision of the paper. KSL, ZH, ACI, and MJL contributed to the study design, data extraction, and analysis and interpretation of data. All authors proofread and approved the submitted version of the paper. The paper contents have not been previously presented elsewhere. All authors have read and approved this manuscript for publication and report no financial disclosures.

\section{Conflicts of Interest}

None declared.

\section{Multimedia Appendix 1}

Databases and search terms used.

[DOCX File, 14 KB-Multimedia Appendix 1]

\section{Multimedia Appendix 2}

PRISMA (Preferred Reporting Items for Systematic Reviews and Meta-Analyses) checklist for the systematic review of the use of blockchain technology in the health care sector.

[DOCX File, 29 KB-Multimedia Appendix 2]

\section{References}

1. Norris AC. Current trends and challenges in health informatics. Health Informatics J 2016 Jul 25;8(4):205-213. [doi: $10.1177 / 146045820200800407]$

2. Nguyen Q, Naguib R, Ghani MA, Bali R, Marshall I, Phuong N, et al. An analysis of the healthcare informatics and systems in Southeast Asia: A current perspective from seven countries. Int J Electron Healthc 2008;4(2):184. [doi: 10.1504/ijeh.2008.019792]

3. Georgiou A. Health informatics and evidence-based medicine - More than a marriage of convenience? Health Informatics J 2016 Sep 14;7(3-4):127-130. [doi: 10.1177/146045820100700303]

4. Ismail NI, Abdullah NH, Shamsuddin A. Adoption of hospital information system (HIS) in Malaysian public hospitals. Procedia Soc Behav Sci 2015 Jan;172:336-343. [doi: 10.1016/j.sbspro.2015.01.373]

5. Peterson K, Deeduvanu R, Kanjamala P, Boles K. A blockchain-based approach to health information exchange networks. HealthIT.gov. 2016. URL: https://www.healthit.gov/sites/default/files/12-55-blockchain-based-approach-final.pdf [accessed 2019-08-08]

6. Zhang P, White J, Schmidt DC, Lenz G. Applying software patterns to address interoperability challenges in blockchain-based healthcare apps. ArXiv Preprint posted online on June 5, 2017 [FREE Full text]

7. Böhme R, Christin N, Edelman B, Moore T. Bitcoin: Economics, technology, and governance. J Econ Perspect 2015 May 01;29(2):213-238. [doi: 10.1257/jep.29.2.213]

8. Dwyer GP. The economics of Bitcoin and similar private digital currencies. J Financ Stab 2015 Apr;17:81-91. [doi: 10.1016/j.jfs.2014.11.006]

9. Mettler M. Blockchain technology in healthcare: The revolution starts here. In: Proceedings of the 18th International Conference on e-Health Networking, Applications and Services. 2016 Presented at: 18th International Conference on e-Health Networking, Applications and Services; Sepember 14-17, 2016; Munich, Germany. [doi: 10.1109/healthcom.2016.7749510]

10. Yli-Huumo J, Ko D, Choi S, Park S, Smolander K. Where is current research on blockchain technology?-A systematic review. PLoS One 2016;11(10):e0163477 [FREE Full text] [doi: 10.1371/journal.pone.0163477] [Medline: 27695049] 
11. Dybå T, Dingsøyr T. Empirical studies of agile software development: A systematic review. Inf Softw Technol 2008 Aug;50(9-10):833-859. [doi: 10.1016/j.infsof.2008.01.006]

12. Petersen K, Feldt R, Mujtaba S, Mattsson M. Systematic mapping studies in software engineering. In: Proceedings of the 12th International Conference on Evaluation and Assessment in Software Engineering. 2008 Presented at: 12th International Conference on Evaluation and Assessment in Software Engineering; June 26-27, 2008; Bari, Italy. [doi: 10.14236/ewic/ease2008.8]

13. Hölbl M, Kompara M, Kamišalić A, Nemec Zlatolas L. A systematic review of the use of blockchain in healthcare. Symmetry 2018 Oct 10;10(10):470. [doi: 10.3390/sym10100470]

14. Maslove DM, Klein J, Brohman K, Martin P. Using blockchain technology to manage clinical trials data: A proof-of-concept study. JMIR Med Inform 2018 Dec 21;6(4):e11949 [FREE Full text] [doi: 10.2196/11949] [Medline: 30578196]

15. Benchoufi M, Porcher R, Ravaud P. Blockchain protocols in clinical trials: Transparency and traceability of consent. F1000Res 2017;6:66 [FREE Full text] [doi: 10.12688/f1000research.10531.5] [Medline: 29167732]

16. Ichikawa D, Kashiyama M, Ueno T. Tamper-resistant mobile health using blockchain technology. JMIR Mhealth Uhealth 2017 Jul 26;5(7):e111 [FREE Full text] [doi: 10.2196/mhealth.7938] [Medline: 28747296]

17. Azaria A, Ekblaw A, Vieira T, Lippman A. MedRec: Using blockchain for medical data access and permission management. In: Proceedings of the 2nd International Conference on Open and Big Data. 2016 Presented at: 2nd International Conference on Open and Big Data; August 22-24, 2016; Vienna, Austria p. 22-24. [doi: 10.1109/obd.2016.11]

18. Cunningham J, Ainsworth J. Enabling patient control of personal electronic health records through distributed ledger technology. Stud Health Technol Inform 2017;245:45-48. [Medline: 29295049]

19. Fan K, Wang S, Ren Y, Li H, Yang Y. MedBlock: Efficient and secure medical data sharing via blockchain. J Med Syst 2018 Jun 21;42(8):136. [doi: 10.1007/s10916-018-0993-7] [Medline: 29931655]

20. Li H, Zhu L, Shen M, Gao F, Tao X, Liu S. Blockchain-based data preservation system for medical data. J Med Syst 2018 Jun 28;42(8):141. [doi: 10.1007/s10916-018-0997-3] [Medline: 29956058]

21. Liu J, Li X, Ye L, Zhang H, Du X, Guizani M. BPDS: A blockchain based privacy-preserving data sharing for electronic medical records. In: Proceedings of the 2018 IEEE Global Communications Conference. 2018 Presented at: 2018 IEEE Global Communications Conference; December 9-13, 2018; Abu Dhabi, United Arab Emirates p. 9-13. [doi: 10.1109/glocom.2018.8647713]

22. Mendes D, Rodrigues IP, Fonseca C, Lopes MJ, García-Alonso JM, Berrocal J. Anonymized distributed PHR using blockchain for openness and non-repudiation guarantee. Stud Health Technol Inform 2018;255:170-174. [Medline: 30306930]

23. Nagasubramanian G, Sakthivel RK, Patan R, Gandomi AH, Sankayya M, Balusamy B. Securing e-health records using keyless signature infrastructure blockchain technology in the cloud. Neural Comput Appl 2018 Nov 30;32(3):639-647. [doi: $10.1007 / \mathrm{s} 00521-018-3915-1$ ]

24. Zhang P, White J, Schmidt DC, Lenz G, Rosenbloom ST. FHIRChain: Applying blockchain to securely and scalably share clinical data. Comput Struct Biotechnol J 2018;16:267-278 [FREE Full text] [doi: 10.1016/j.csbj.2018.07.004] [Medline: 30108685]

25. Cichosz SL, Stausholm MN, Kronborg T, Vestergaard P, Hejlesen O. How to use blockchain for diabetes health care data and access management: An operational concept. J Diabetes Sci Technol 2019 Mar;13(2):248-253 [FREE Full text] [doi: 10.1177/1932296818790281] [Medline: 30047789]

26. Omar AA, Bhuiyan MZA, Basu A, Kiyomoto S, Rahman MS. Privacy-friendly platform for healthcare data in cloud based on blockchain environment. Future Gener Comput Syst 2019 Jun;95:511-521. [doi: 10.1016/j.future.2018.12.044]

27. Angeletti F, Chatzigiannakis I, Vitaletti A. The role of blockchain and IoT in recruiting participants for digital clinical trials. In: Proceedings of the 25th International Conference on Software, Telecommunications and Computer Networks. 2017 Presented at: 25th International Conference on Software, Telecommunications and Computer Networks; September 21-23, 2017; Split, Croatia. [doi: 10.23919/SOFTCOM.2017.8115590]

28. Kleinaki A, Mytis-Gkometh P, Drosatos G, Efraimidis PS, Kaldoudi E. A blockchain-based notarization service for biomedical knowledge retrieval. Comput Struct Biotechnol J 2018;16:288-297 [FREE Full text] [doi:

10.1016/j.csbj.2018.08.002] [Medline: 30181840]

29. Nugent T, Upton D, Cimpoesu M. Improving data transparency in clinical trials using blockchain smart contracts. F1000Res 2016;5:2541 [FREE Full text] [doi: 10.12688/f1000research.9756.1] [Medline: 28357041]

30. Liang X, Zhao J, Shetty S, Liu J, Li D. Integrating blockchain for data sharing and collaboration in mobile healthcare applications. In: Proceedings of the 28th Annual International Symposium on Personal, Indoor, and Mobile Radio Communications. 2017 Presented at: 28th Annual International Symposium on Personal, Indoor, and Mobile Radio Communications; October 8-13, 2017; Montreal, QC. [doi: 10.1109/PIMRC.2017.8292361]

31. Saravanan M, Shubha R, Mary A. SMEAD: A secured mobile enabled assisting device for diabetics monitoring. In: Proceedings of the 11th IEEE International Conference on Advanced Networks and Telecommunications Systems. 2018 Presented at: 11th IEEE International Conference on Advanced Networks and Telecommunications Systems; December 17-20, 2017; Bhubaneswar, India. [doi: 10.1109/ants.2017.8384099]

32. Bocek T, Rodrigues B, Strasser T, Stiller B. Blockchains everywhere - A use-case of blockchains in the pharma supply-chain. In: Proceedings of the IFIP/IEEE Symposium on Integrated Network and Service Management. 2017 Presented at: IFIP/IEEE 
Symposium on Integrated Network and Service Management; May 8-12, 2017; Lisbon, Portugal. [doi:

10.23919/inm.2017.7987376]

33. Zhou L, Wang L, Sun Y. MIStore: A blockchain-based medical insurance storage system. J Med Syst 2018 Jul 02;42(8):149 [FREE Full text] [doi: 10.1007/s10916-018-0996-4] [Medline: 29968202]

34. Kotsiuba I, Velvkzhanin A, Yanovich Y, Bandurova I, Dyachenko Y, Zhygulin V. Decentralized e-Health architecture for boosting healthcare analytics. In: Proceedings of the 2nd World Conference on Smart Trends in Systems, Security and Sustainability. 2019 Presented at: 2nd World Conference on Smart Trends in Systems, Security and Sustainability; October 30-31, 2018; London, UK. [doi: 10.1109/worlds4.2018.8611621]

35. Talukder A, Chaitanya M, Arnold D, Sakurai K. Proof of disease: A blockchain consensus protocol for accurate medical decisions and reducing the disease burden. In: Proceedings of the 2018 IEEE SmartWorld, Ubiquitous Intelligence \& Computing, Advanced \& Trusted Computing, Scalable Computing \& Communications, Cloud \& Big Data Computing, Internet of People and Smart City Innovations. 2018 Presented at: 2018 IEEE SmartWorld, Ubiquitous Intelligence \& Computing, Advanced \& Trusted Computing, Scalable Computing \& Communications, Cloud \& Big Data Computing, Internet of People and Smart City Innovations; October 7-11, 2018; Guangzhou, China. [doi: 10.1109/smartworld.2018.00079]

\author{
Abbreviations \\ BPDS: blockchain-based privacy-preserving data sharing \\ EHR: electronic health record \\ EMR: electronic medical record \\ FHIR: Fast Healthcare Interoperability Resources \\ HI: health informatics \\ HIS: hospital information system \\ IT: information technology \\ KSI: keyless signature infrastructure \\ MeSH: Medical Subject Headings \\ mHealth: mobile health \\ MIT: Massachusetts Institute of Technology \\ NEM: New Economy Movement \\ PRISMA: Preferred Reporting Items for Systematic Reviews and Meta-Analyses \\ Q1: question 1 \\ Q2: question 2 \\ Q3: question 3 \\ Q4: question 4
}

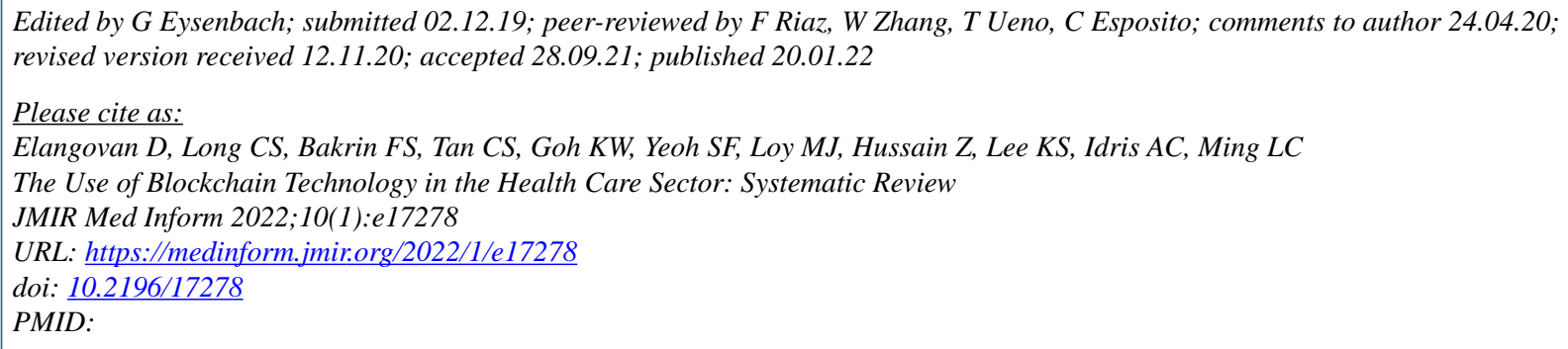

(CDeepa Elangovan, Chiau Soon Long, Faizah Safina Bakrin, Ching Siang Tan, Khang Wen Goh, Siang Fei Yeoh, Mei Jun Loy, Zahid Hussain, Kah Seng Lee, Azam Che Idris, Long Chiau Ming. Originally published in JMIR Medical Informatics (https://medinform.jmir.org), 20.01.2022. This is an open-access article distributed under the terms of the Creative Commons Attribution License (https://creativecommons.org/licenses/by/4.0/), which permits unrestricted use, distribution, and reproduction in any medium, provided the original work, first published in JMIR Medical Informatics, is properly cited. The complete bibliographic information, a link to the original publication on https://medinform.jmir.org/, as well as this copyright and license information must be included. 